\title{
Erratum to: Neurobiology of Substance Abuse
}

\author{
André Bedendo, André Luiz Monezi Andrade and Ana Regina Noto
}

\section{Erratum to:}

\section{Chapter 2 in: A.L.M. Andrade and D. De Micheli (eds.), Innovations in the Treatment of Substance Addiction, DOI 10.1007/978-3-319-43172-7_2}

The names of the authors, respectively, "Denise De Micheli" and "Adriana Scatena" were included incorrectly in the published version of Chapter 2. The erratum chapter and the book have been updated with the changes.

The updated original online version for this chapter can be found at 10.1007/978-3-319-43172-7_2

\begin{abstract}
A. Bedendo ( $\square)$ - A.L.M. Andrade · A.R. Noto Departamento de Psicobiologia, Universidade Federal de São Paulo, Rua Botucatu, 862 - 1o Andar, Edifício de Ciências Biomédicas, São Paulo, SP 04023-062, Brazil e-mail: andrebedendo@gmail.com
\end{abstract}

A.L.M. Andrade

e-mail: andremonezi@gmail.com

A.R. Noto

e-mail: anareginanoto@gmail.com; ana.noto@unifesp.br 